\title{
A SOCIEDADE INTERNACIONAL CONTEMPORÂNEA E A GÊNESE E IMPORTÂNCIA DA ORGANIZAÇÃO MUNDIAL DO COMÉRCIO (OMC)
}

Natália Villas Bôas Zanelatto ${ }^{1}$

\section{CONSIDERAÇÕES INICIAIS}

O tema central do presente trabalho consiste no estudo da Organização Mundial de Comércio (OMC) e sua gênese e desenvolvimento até a estrutura que a conforma atualmente. Para tanto, analisar-se-á a sociedade internacional contemporânea e o papel nela desempenhado pelas organizações internacionais, os antecedentes históricos da criação da OMC e o seu surgimento e, finalmente, o seu status atual e seus objetivos enquanto mais importante e controversa das organizações do cenário internacional.

\section{A SOCIEDADE INTERNACIONAL CONTEMPORÂNEA E AS ORGANIZAÇÕES INTERNACIONAIS}

\subsection{O ESTADO E O DIREITO - AS MUTAÇÕES DO ESTADO NA ERA DA GLOBALIZAÇÃO}

O liberalismo político clássico legou-nos um modelo de Estado e de Direito que permanece na base dogmática jurídica, o qual tem como pressupostos a ligação do Direito ao Poder Legislativo unilateral do Estado, a pertença dos indivíduos ao território de um único Estado e de um único Direito e a finalidade deste de alcançar o interesse geral da comunidade nacional. Contudo, incontestáveis mutações foram sofridas por este modelo diante da globalização e seus efeitos. Neste sentido, tal fenômeno precisa, quando da análise de novos modelos de Estado e de Direito emergentes, ser a eles relacionado. Dentre as características do fenômeno da globalização, Antonio Manuel Hespanha destaca:

\footnotetext{
${ }^{1}$ Acadêmica do $5^{\circ}$ ano do curso de Direito da UFPR, pesquisadora do Núcleo de Estudos de Direito Internacional e do Núcleo de Pesquisas do Mercosul.
}

Revista Brasileira de Direito Internacional, Curitiba, v.7, n.7, jan./jun.2008 
i) O surgimento de uma economia global com transações mais rápidas e mais densas entre os seus setores como decorrência de avanços tecnológicos no âmbito da telecomunicação e transportes, nova divisão internacional do trabalho, atuação de empresas transnacionais e os efeitos de políticas da liberdade de comércio e de movimentos de capitais;

ii) Migrações internacionais temporárias, desenraizando os conceitos de domicílio fixo e nacionalidade única do psicológico dos indivíduos e gerando consequiências políticas;

iii) Desenvolvimento de "necessidades globais", relevantes sobretudo se consideradas globalmente, e não tanto nacional ou localmente;

iv) Criação de culturas cosmopolitas, ao lado das culturas locais;

v) Desterritorialização das identidades sociais, desafiando a hegemonia dos Estados-Nação e promovendo formas de identificação sobrepostas, permeáveis e múltiplas;

vi) Aparecimento de entidades não estatais como sujeitos da comunidade internacional, com peso econômico e social crescente, tendendo a superar o do conjunto dos Estados-Nação tradicionais. ${ }^{2}$

Dentre as referidas faces da globalização, enfoca-se, para os fins do presente trabalho, o surgimento de entidades que não possuem vínculo institucional a Estados, mas detém status de sujeitos internacionais, às quais é conferido crescente respeito pela comunidade internacional, conforme se abordará adiante. Assim, retomando as lições de HESPANHA:

Neste sentido, importa destacar a função reguladora adquirida, não apenas por organizações internacionais, sobretudo no domínio económico, (GATT [agora Organização Mundial do Comércio, WTO/OMC], FMI, G8, Banco Mundial) ou das novas tecnologias da comunicação (v.g. ITU), mas também por empresas e organizações transnacionais.

Com efeito, tal mundo de novas unidades econômicas (e também regulatórias) transforma-se em um mundo de unidades, igualmente novas, de natureza política e normativa, uma vez que cada unidade econômica constitui um centro de poder e de emissão de normas jurídicas, sejam elas decorrentes de contrato, de regulação genérica, técnicas, etc. $E$ assim, esse conjunto de unidades requer uma disciplina obrigatória para todos os participantes de transações no mundo globalizado, i.e., um Direito do mercado globalizado.

\footnotetext{
${ }^{2}$ HESPANHA, Antonio Manuel. O Caleidoscópio do Direito: O Direito e a Justiça nos Dias e no Mundo de Hoje. Coimbra: Almedina, 2007. P 348
}

Revista Brasileira de Direito Internacional, Curitiba, v.7, n.7, jan./jun.2008 
Neste sentido, tal direito não poderá provir de direitos estatais, o que caracterizaria uma contradição ontológica, conforme Hespanha. O autor inicia, então, um raciocínio com intuito de buscar a fonte adequada do Direito do mercado globalizado. Este não decorreria, segundo ele, de tratados internacionais, já que se torna cada vez mais claro que a dinâmica da sociedade globalizada é incompatível com o ritmo lento da criação daqueles. Um Direito internacional puramente consuetudinário (lex mercatoria), tampouco seria adequado, já que o costume exige continuidade no tempo, da qual não se dispõe. Outrossim, uma regulação por meio regras geraria o inconveniente de demasiada rigidez diante das constantes mutações da sociedade hodierna. Há de ser, desta feita, um Direito calcado na maleabilidade de princípios e na prática quotidiana e imediata do mercado.

Defende-se, atualmente, que esta maleabilidade normativa poderia advir de um conjunto de valores cosmopolitas, comuns a todos os sujeitos da comunidade global, de valores cosmopolitas. E que esta comunidade global, que criaria o conjunto de valores, seria a comunidade dos sujeitos econômicos transnacionais.

No que concerne a sua efetividade, Hespanha dispõe que, apesar da dispersão geográfica e da inexistência de uma garantia coercitiva estatal do seu cumprimento, a eficácia de tal ordem normativa dar-se-á em virtude das sanções sociais, que oferecem meios mais baratos e mais efetivos de cobrar créditos difíceis, e sua flexibilidade facilitará as transações econômicas.

Outro elemento de eficácia e flexibilidade desta ordem que merece destaque é o fato de que valores "antipáticos para o mercado" - como a defesa dos interesses nacionais, a garantia dos direitos dos cidadãos e a defesa do meio ambiente como habitat comum - a despeito não representarem valores do mercado internacional, encontram porta-vozes em organizações nãogovernamentais. Tais organizações, apesar de terem menor poder de influência na gestação de normas efetivas no plano internacional, contribuem para a criação de valores variados, que também devem ser incorporados na formação de um direito global. 


\subsection{A GÊNESE E AS FEIÇÕES DOS REGIMES E DAS} ORGANIZAÇÕES INTERNACIONAIS

O século $X X$ foi o palco, em razão da intensificação das relações entre os Estados, ora pacíficas, ora nem tanto, do surgimento do que se convencionou denominar "regime internacional". Tal expressão, criada por Stephen D. Krasner e aceita por grande parte da doutrina internacional, pretende sintetizar o conjunto de princípios, normas, regras e procedimentos de tomada de decisão, implícitos ou explícitos, em torno dos quais as expectativas dos atores internacionais convergem dentro de uma específica área das relações internacionais.

Regimes can be defined as sets of implicit or explicit principles, norms, rules, and decision- making procedures around which actors' expectations converge in a given area of international relations. ${ }^{3}$

Assim, os elementos que compõem o regime são conceituados pelo autor da seguinte maneira: (i) princípios são crenças de fato, causação e retitude; (ii) normas são padrões de comportamento definidos em termos de direitos e obrigações; (iii) regras são prescrições específicas de ação e; (iv) procedimentos de tomada de decisão são práticas prevalecentes para encontrar e implementar a escolha coletiva. Segundo a concepção de regime de Krasner, portanto, mudanças em regras e procedimentos de tomada de decisão constituem mudanças no regime, ao passo que alterações de princípios e normas caracterizam uma mudança de regime. ${ }^{4}$

No que concerne a importância do regime internacional, o autor apresenta três diferentes correntes doutrinárias, (i) a da "tradição Grociana" (Grotian tradition), que concebe os regimes internacionais como característica essencial do sistema internacional, uma vez em que padrões de conduta

\footnotetext{
${ }^{3}$ KRASNER, Stephen D. Structural Causes and Regime Consequences: regimes as intervening variables. In: KRASNER, Stephen D. (org). International Regimes. Ithaca and London: Cornell University Press, 1995, p. 1.

${ }^{4}$ Ibdem, p. 2-4. De modo diverso da doutrina majoritária brasileira, notadamente J. J. Gomes Canotilho, para Krasner a distinção entre norma e regra não se dá no plano do grau de abstração, determinabilidade ou fundamentalidade de uma e outra, o que pode dificultar a diferenciação em casos concretos.
}

Revista Brasileira de Direito Internacional, Curitiba, v.7, n.7, jan./jun.2008 
sempre estão vinculados a normas reconhecidas; (ii) a estruturalista (conventional structural view), que afirma que o conceito de regime é pernicioso e ofusca e obscura os interesses e relações de poder, que são as efetivas causas de comportamento do sistema internacional; (iii) a estruturalista modificada (modified structural view) que acredita que Estados soberanos procuram maximizar seus interesses e poderes. Todavia, segundo esta última corrente, cálculos individuais de interesse não proporcionam o alcance de objetivos internacionais, o que só é possível através da coordenação da conduta dos Estados. Sendo assim, o regime internacional deriva de acordos voluntariamente firmados entre atores internacionais juridicamente iguais.

Conforme defende Michels, a opção que melhor espelha o quadro atual das relações internacionais é a estruturalista modificada, já que a soberania estatal ainda está longe de ser superada, mas os regimes internacionais vêm adquirindo grande relevância no âmbito internacional. Tal é justificado pelo autor pela institucionalização dos regimes internacionais, resultando em

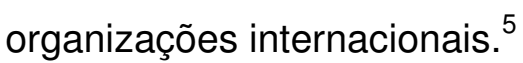

Respaldando tal linha de raciocínio, Cretella Neto destaca:

Quando as relações bilaterais baseadas na existência de relações diplomáticas ou missões se revelaram inadequadas para lidar com situações mais complexas, derivadas de problemas que afetavam não apenas dois, mas muitos Estados, uma solução precisava ser encontrada para representar, no mesmo foro, os interesses comuns de todos os Estados. ${ }^{6}$

Neste sentido, conforme o autor, as organizações internacionais, tais como as conhecemos atualmente, são o resultado de lenta evolução das relações bilaterais ou multilaterais entre os Estados, cuja origem pode ser localizada no início do século XIX, mais especificamente no período compreendido entre os anos de 1815 e 1914. Tal momento histórico, seguinte à queda de Napoleão, foi caracterizado por relativa paz e progresso

\footnotetext{
${ }^{5}$ MICHELS, Gilson Wessler. O Papel da Organização Mundial do Comércio no Processo de Aproximação das Ordens Tributárias Nacionais. Tese Doutorado. Florianópolis, 2009, p. 26

${ }^{6}$ CRETELLA NETO, José. Teoria Geral das Organizações Internacionais. São Paulo: Saraiva, 2007, p. 18-19.
}

Revista Brasileira de Direito Internacional, Curitiba, v.7, n.7, jan./jun.2008 
tecnológico e científico sem precedentes, sem mencionar os avanços nos meios de comunicação.

No que concerne a evolução das organizações internacionais, surgidas timidamente, de modo incipiente, limitado e despretensioso (dispunham, em geral, apenas de uma Secretaria e pequeno contingente administrativo), Cretella Neto ressalta que aumentaram em número, amadureceram durante mais de um século e, a partir da criação da Organização das Nações Unidas (ONU) em 1945, ganharam cada vez espaço enquanto entidades políticojurídicas no universo do Direito Internacional. Deste modo, proliferaram-se na segunda metade do século $X X$ e prevê-se a continuidade desse processo durante o século $\mathrm{XXI}$, aliado à consolidação daquelas já existentes. Nos termos do autor:

Por isso, é apropriado chamar o século XIX - aqui melhor entendido como o período entre 1815 e 1914 - de "era de preparação para as organizações internacionais"; o período entre 1914 e 1945, de "era de desenvolvimento das organizações internacionais; e o período posterior a 1945, de "era de consolidação das organizações internacionais", o que mostra que as organizações internacionais são, efetivamente, um fenômeno do século XX.

Hodiernamente, as organizações internacionais enfrentam e procuram solucionar, mediante a aplicação do regime internacional que lhes deram origem, as questões surgidas na sociedade internacional, o que denota que, apesar do aumento de tensões, a sociedade internacional parece unir-se cada vez mais para enfrentar problemas comuns, de variada natureza.

Merece destaque, nesse contexto, a evolução do comportamento dos Estados, que vêm aceitando e implementando as obrigações que lhes são impostas por participarem de organizações internacionais, bem como as limitações aos poderes e liberdades decorrentes de suas soberanias. Contudo, os entes estatais apresentam preocupações em relação ao tema devido à superposição de autoridades (legislativa e judicial) e de competências, e também no que tange as despesas geradas pelas organizações, cujos investimentos são oriundos de tributos pagos pelos cidadãos dos Estados. 
O autor, justificando a necessidade de estudos jurídicos mais profundos sobre as organizações internacionais, aponta que deles dependem uma compreensão adequada da evolução pela qual passou a sociedade internacional e, consequentemente, o Direito Internacional.

\section{A ORGANIZAÇÃO MUNDIAL DO COMÉRCIO}

\subsection{ANTECEDENTES HISTÓRICOS}

As origens do comércio internacional remontam a um período distante na história. De acordo com Barral, seria provavelmente justo dizer que os primeiros comerciantes internacionais foram os fenícios, os quais, séculos antes de Cristo, já haviam descoberto as vantagens das trocas de mercadorias entre regiões com diferentes ofertas e demandas. Desde então, a participação do comércio na criação de riquezas sofreu alterações de época a época, a depender do momento histórico e do povo. ${ }^{7}$

O grande salto do comércio no sentido de sua mundialização ocorreu ao final do século XV, com o avanço dos povos ibéricos na rota das Índias e da América. A partir das descobertas de novos territórios surge a troca internacional de mercadorias com fluxos organizados, e após o século XVI a verificação de que o espaço econômico não coincidia com as fronteiras políticas conferiu novos moldes ao comércio internacional. ${ }^{8}$

Conforme se observou no capítulo anterior, um longo período de paz e prosperidade econômica marcou o século XIX, apresentando seus resultados positivos no início do século XX. A esse período corresponde crescente regulamentação comercial, sobretudo entre os países desenvolvidos. Contudo, a crise da bolsa de Nova lorque constituiu um entrave a referido desenvolvimento da regulação, já que os Estados passaram a descumprir as regras comerciais e adotaram 0 unilateralismo nas decisões políticas. $O$ agravamento da crise culminou, então, na Segunda Guerra Mundial.

\footnotetext{
${ }^{7}$ BARRAL, Welber Oliveira. O Comércio Internacional. Belo Horizonte: Del Rey, 2007, p. 25.

${ }^{8}$ MICHELS, Gilson Wessler. Tese: O Papel da Organização Mundial do Comércio no Processo de Aproximação das Ordens Tributárias Nacionais. Florianópolis, 2009, p. 55.
}

Revista Brasileira de Direito Internacional, Curitiba, v.7, n.7, jan./jun.2008 
Barral, a respeito deste período histórico, observa que o intuito de cooperação foi o espírito do tempo que permitiu que acordos históricos fossem alcançados ao final da guerra.

Parece ser a sina da história humana que somente grandes tragédias parecem ter o poder de catalizar a cooperação. O flagelo da Segunda Guerra tornou evidente a necessidade de cooperação, com a criação de uma estrutura política que pudesse garantir a paz, e de uma estrutura econômica que pudesse evitar a instabilidade. ${ }^{9}$

\subsection{BRETTON WOODS E O GATT}

Antes mesmo do término do conflito, articulou-se a criação de uma grande organização internacional voltada à manutenção da paz. À Organização das Nações Unidas (ONU) foram conferidos, portanto, mecanismos de solução de conflitos e possibilidades de intervenção superiores à tentativa anterior, consubstanciada na Liga das Nações.

Já no que concerne o plano econômico, os representantes das potências ocidentais reuniram-se em uma grande fazenda dos Estados Unidos da América, Bretton Woods, em uma tentativa de reestruturação, e decidiram pela criação de instituições multilaterais que promovessem a cooperação e a estabilidade nas relações econômicas internacionais. Desta reunião decorreram, portanto, o Fundo Monetário Internacional (FMI), o Banco Internacional para a Reconstrução e Desenvolvimento (BIRD ou Banco Mundial) e a Organização Internacional do Comércio (OIC).

Enfocando no objeto de análise do presente estudo, o qual possibilita a adequada compreensão da evolução do sistema multilateral de comércio, destaca-se que nas negociações que se seguiram a Bretton Woods, a fim de desenhar a OIC, elaborou-se em 1948 a Carta de Havana. Esta, por sua vez, era dividida em três partes: (i) a primeira dedicada à criação da OIC; (ii) a segunda contendo regras de redução de tarifas; (iii) e a terceira composta de regras gerais a serem seguidas no processo de redução tarifária.

${ }^{9}$ BARRAL, Welber Oliveira. O Comércio Internacional. Belo Horizonte: Del Rey, 2007, p. 26.

Revista Brasileira de Direito Internacional, Curitiba, v.7, n.7, jan./jun.2008 
Desta feita, uma vez concluída a Carta de Havana, os Estados deveriam ratificá-la, o que não se verificou no Congresso estadunidense, por diversos motivos de ordem política. Tal recusa norte-americana desencadeou o desinteresse dos demais Estados na criação de uma organização internacional de comércio da qual não participaria a maior potência comercial.

Diante desses acontecimentos, a OIC nunca chegou a ser criada, vigorando somente, como protocolo de aplicação provisória, a segunda e a terceira partes da Carta de Havana, que originaram o Acordo Geral sobre Tarifas e Comércio (General Agreement on Tariffs and Trade, origem da sigla GATT). Entrou em vigor, portanto, em $1^{\circ}$ de janeiro de 1948, uma estrutura jurídica provisória, na qual faltava o principal pilar - uma organização internacional. ${ }^{10}$

O chamado "GATT 1947" foi redigido de forma pouco precisa ("loosely drafted"), justamente porque nunca se pretendeu que constituísse uma organização internacional, contém disposições ambíguas e sofreu gradativas alterações e ampliações no seu sistema de solução de controvérsias. Conforme se verá adiante, foi este o instrumento que regeu o comércio internacional entre 1948 e 1995, sob uma ótica relativamente liberal. ${ }^{11}$

\subsection{OS AVANÇOS DA RODADA DO URUGUAI}

O GATT, desempenhando papel de suma importância no comércio internacional do século XXI, começou a revelar sinais de esgotamento e falta de capacidade para gerir a complexidade das relações comerciais multilaterais. Verificou-se, nesse contexto, a premente necessidade de reforma no sistema comercial multilateral diante dos seguintes fatos: (i) descumprimentos sucessivos das regras comerciais multilaterais; (ii) ausência de coerência entre os mais de duzentos instrumentos jurídicos que compunham o sistema do

\footnotetext{
${ }^{10}$ BARRAL, Welber Oliveira. O Comércio Internacional. Belo Horizonte: Del Rey, 2007, p. 2730.

${ }^{11}$ CRETELLA NETO, José. Teoria Geral das Organizações Internacionais. São Paulo: Saraiva, 2007, p. 34.
}

Revista Brasileira de Direito Internacional, Curitiba, v.7, n.7, jan./jun.2008 
GATT; (iii) aumento das tensões comerciais, (iv) lacunas de regulação em importantes domínios do comércio internacional.

Com o objetivo de fazer frente a esses problemas, iniciou-se oficialmente a Rodada Uruguai (Uruguay Round) em 20 de setembro de 1986, em Punta del Este, consistindo em uma rodada de negociações comerciais multilaterais marcada por dois compromissos fundamentais: cláusula de standstill e cláusula de roll-back. A primeira impunha a obrigação de não se instaurarem novas medidas protecionistas até a conclusão das negociações, evitando que aquelas fossem criadas com o fim de melhorar a posição negociadora dos Estados; já a segunda determinava que as medidas protecionistas fossem colocadas em conformidade com as regras do GATT, ou mesmo eliminadas até o término das negociações. A Rodada, com previsão de duração de quatro anos, acabou por durar oito anos.

Com efeito, em 15 de abril de 1994, na Conferência de Marraqueche, a Rodada Uruguai foi formalmente concluída com a aposição da assinatura de ministros de 117 países e os representantes da União Européia na Ata Final. Tal Ata incorpora o Acordo que institui o Organização Mundial de Comércio, doravante Acordo Constitutivo da OMC, quatro Anexos e várias Declarações e Decisões Ministeriais. Em seguida, foi confirmada a data de entrada em vigor do Acordo Constitutivo da OMC e dos respectivos Anexos, $1^{\circ}$ de janeiro de 1995.

Cinqüenta anos depois de Bretton Woods, finalmente se materializava a pretensão de uma organização multilateral que pudesse regulamentar as relações comerciais num plano multilateral, tendo a participação da maioria absoluta dos Estados do planeta. ${ }^{12}$

A partir de então, a Organização Mundial do Comércio e diversos acordos comerciais passaram a constituir o fundamento jurídico e institucional do sistema comercial multilateral, consagrando não só os princípios que devem nortear a atividade dos governos quando da formulação e aplicação de suas leis e regulamentos internos em matéria de comércio, como também o quadro

${ }^{12}$ BARRAL, Welber Oliveira. O Comércio Internacional. Belo Horizonte: Del Rey, 2007, p. 34.

Revista Brasileira de Direito Internacional, Curitiba, v.7, n.7, jan./jun.2008 
no qual as relações comerciais entre os países evoluem através de um processo coletivo de discussão, de negociação e de decisão. ${ }^{13}$

2.4 STATUS JURÍDICO, OBJETIVOS E ORGANIZAÇÃO INSTITUCIONAL DA OMC

O Acordo Constitutivo da OMC consiste no instrumento que dispõe sobre o regime jurídico desta organização internacional. Adotando-se uma ordem didática, pode-se dizer que quanto à natureza jurídica da $\mathrm{OMC}$, o Acordo determina, em seu artigo VIII, que "A OMC será dotada de personalidade jurídica, sendo-lhe concedida pelos seus Membros a capacidade jurídica que se afigure necessária para o exercício de suas funções.", assim como devem ser-lhe concedidos pelos seus Membros os privilégios e imunidades necessários ao exercício de suas funções. ${ }^{14}$

No que tange o escopo da organização, o artigo III do Acordo dispõe que suas funções consistem em:

(i) facilitar a aplicação, administração e funcionamento deste Acordo e dos demais acordos comerciais multilaterais ou plurilaterais;

(ii) servir como foro para as negociações sobre relações comerciais entre seus Membros;

(iii) assegurar a aplicação do "Entendimento relativo às Normas e Procedimentos sobre Solução de Controvérsias" (ESC);

(iv) assegurar a aplicação do Mecanismo de Exame das Políticas Comerciais;

(v) cooperar, quando necessário, com o FMI e com o Banco Mundial, a fim de garantir coerência às políticas econômicas mundiais. ${ }^{15}$

\footnotetext{
13 MICHELS, Gilson Wessler. Tese: O Papel da Organização Mundial do Comércio no Processo de Aproximação das Ordens Tributárias Nacionais. Florianópolis, 2009, p. 62.

${ }^{14}$ Agreement Establishing the World Trade Organization, Article VIII, "1. The WTO shall have legal personality, and shall be accorded by each of its Members such legal capacity as may be necessary for the exercise of its functions. 2. The WTO shall be accorded by each of its Members such privileges and immunities as are necessary for the exercise of its functions." Disponível em

${ }^{15}$ Agreement Establishing the World Trade Organization, Article III: "Functions of the WTO

1. The WTO shall facilitate the implementation, administration and operation, and further the objectives, of this Agreement and of the Multilateral Trade Agreements, and shall also provide the framework for the implementation, administration and operation of the Plurilateral Trade Agreements.

2. The WTO shall provide the forum for negotiations among its Members concerning their multilateral trade relations in matters dealt with under the agreements in the Annexes to this
}

Revista Brasileira de Direito Internacional, Curitiba, v.7, n.7, jan./jun.2008 
Conforme assevera Barral, seria difícil indicar qual objetivo prepondera. Enquanto administradora dos acordos comerciais multilaterais, a OMC exerce atividade burocrática, sobretudo no que se refere à implementação dos acordos, ou seja, no acompanhamento da inserção, na ordem jurídica de cada Membro, dos acordos por ele firmados no âmbito da OMC.

Como foro de negociação, ela pretende servir como campo neutro, em que os Estados Membros firmem acordos e promovam o comércio entre si. Tais negociações, há de se convir, não constituem necessariamente situações de igualdade entre os Membros, prevalecendo, portanto, o grau de poder econômico que cada governo detém. Contudo, mesmo diante de tal disparidade, a OMC serve como foro de negociação mais transparente do que à época do GATT, quando as pressões sobre os países economicamente mais fracos eram mais dissimuladas.

Já com relação ao Mecanismo de Solução de Controvérsias, este é considerado uma das principais inovações da Rodada Uruguai. Apesar de sua administração incumbir à $\mathrm{OMC}$, que secretaria o funcionamento dos painéis e do Órgão de Apelação, ela tecnicamente não decide o mérito do conflito. Tal decisão incumbe a um grupo de especialistas, mas pode ser objeto de recurso a instância superior e, posteriormente, deve ser ratificada por todos os Estados Membros. Verifica-se, no entanto, que a decisão final incumbe aos representantes governamentais.

O quarto objetivo trata da aplicação do Mecanismo de Exame de Políticas Comerciais, o qual se traduz na análise das políticas e regras comerciais nacionais. Tal mecanismo busca conferir transparência nas práticas dos Membros que possam se referir ao comércio internacional, já que, ao

Agreement. The WTO may also provide a forum for further negotiations among its Members concerning their multilateral trade relations, and a framework for the implementation of the results of such negotiations, as may be decided by the Ministerial Conference.

3. The WTO shall administer the Understanding on Rules and Procedures Governing the Settlement of Disputes (hereinafter referred to as the "Dispute Settlement Understanding" or "DSU") in Annex 2 to this Agreement.

4. The WTO shall administer the Trade Policy Review Mechanism (hereinafter referred to as the "TPRM") provided for in Annex 3 to this Agreement.

5. With a view to achieving greater coherence in global economic policy-making, the WTO shall cooperate, as appropriate, with the International Monetary Fund and with the International Bank for Reconstruction and Development and its affiliated agencies.

Revista Brasileira de Direito Internacional, Curitiba, v.7, n.7, jan./jun.2008 
exporem suas políticas, eles devem justificar qualquer norma em dissonância dos acordos da OMC. ${ }^{16}$

Por fim, a OMC pretende alcançar coerência na política econômica global, cooperando com o Fundo Monetário Internacional (FMI) e com o Banco Internacional para Reconstrução e Desenvolvimento (BIRD ou Banco Mundial). O primeiro dirige-se, em termos sintéticos, a evitar que irresponsabilidades fiscais de alguns governos contaminem o conjunto do sistema cambial internacional, baseado fundamentalmente na confiança dos meios de troca. $O$ Banco Mundial, por sua vez, visa promover o desenvolvimento dos países subdesenvolvidos. Concatenando seus esforços e adotando políticas em mesmo sentido, OMC, FMI e Banco Mundial adquirem maiores chances de conformarem o comércio internacional conforme pretendem. ${ }^{17}$

\section{CONCLUSÃO}

Conforme se demonstrou, o institucionalismo propiciou a transformação dos regimes internacionais em organizações internacionais, as quais exercem importante papel no condicionamento de condutas na sociedade internacional contemporânea. Verifica-se, diante deste cenário, que os Estados não deixaram de ser os principais atores da cena internacional, mas surgiram outras fontes de direito para além do Estado soberano.

É neste contexto que é criada a OMC, constituindo uma organização internacional composta por um sistema baseado em regras e estruturada a partir de um sofisticado conjunto de órgãos e procedimentos que possibilitam que ela constitua um foro de produção normativa, monitoramento de políticas e normas nacionais referentes ao comércio internacional.

Considerando que o modelo imposto pela OMC deve prevalecer pelos próximos anos, e por prazo imprevisível, dado que é resultado de décadas de evolução do regime internacional de comércio, importa conhecer suas origens,

\footnotetext{
${ }^{16}$ BARRAL, Welber Oliveira. O Comércio Internacional. Belo Horizonte: Del Rey, 2007, p. 4445.

${ }^{17}$ BARRAL, Welber Oliveira. O Comércio Internacional. Belo Horizonte: Del Rey, 2007, p. $27-$ 28.
}

Revista Brasileira de Direito Internacional, Curitiba, v.7, n.7, jan./jun.2008 
sua natureza e seus objetivos, tanto seja para "participar do jogo", quanto para buscar mudanças ou readequações futuras. 